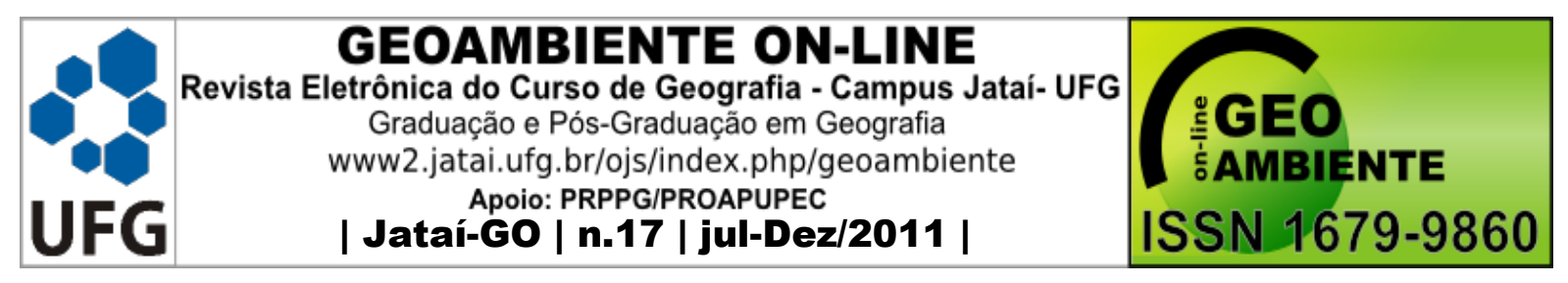

\title{
DETERMINAÇÃO ALTIMÉTRICA E MODELO DIGITAL DE TERRENO PARA A GELEIRA WANDA, ILHA REI GEORGE, POR SISTEMA DE POSICIONAMENTO GLOBAL E NIVELAMENTO TRIGONOMÉTRICO
}

\begin{abstract}
Katia Kellem da Rosa ${ }^{1}$
(1 - Universidade Federal do Rio Grande do Sul, Doutorando em Geociências - UFRGS, katiakellem@gmail.com)

\section{Resumo}

O presente trabalho visa determinar altitudes ortométricas e a geração de Modelo Tridimensional de Superfície na área da geleira Wanda localizada na ilha Rei George, Península Antártica. Devido à dificuldade de acessibilidade logística destes ambientes, coletas temporais de dados de Modelos Numéricos do Terreno deve necessariamente permitir obter dados volumétricos das geleiras para análises temporais, inferência do sentido de fluxo de gelo e ainda mudanças na dinâmica glacial. Dados de GPS obtidos pelo método relativo estático e cinemático com um receptor topográfico de simples frequiência (GTRA) foram pósprocessados para a correção diferencial e as coordenadas altimétricas relativas ao elipsóide foram transformadas para o sistema topográfico local através do cálculo da ondulação geoidal com base no Modelo Geopotencial EGM96. Com os dados obtidos foi gerado o modelo tridimensional de superfície para a geleira Wanda. A análise desse modelo indica um perfil com uma pendente em direção a área frontal. Esta pendente pode estar relacionada à topografia do embasamento rochoso e a perda de massa de gelo pela geleira nas ultimas décadas. Uma superfície de maior declividade, verificada com o modelo, pode proporcionar uma aceleração local da velocidade de fluxo da geleira Wanda.
\end{abstract}

\footnotetext{
Artigo recebido para publicação em 28 de Agosto de 2011

Artigo aprovado para publicação em 20 Dezembro de 2011
} 


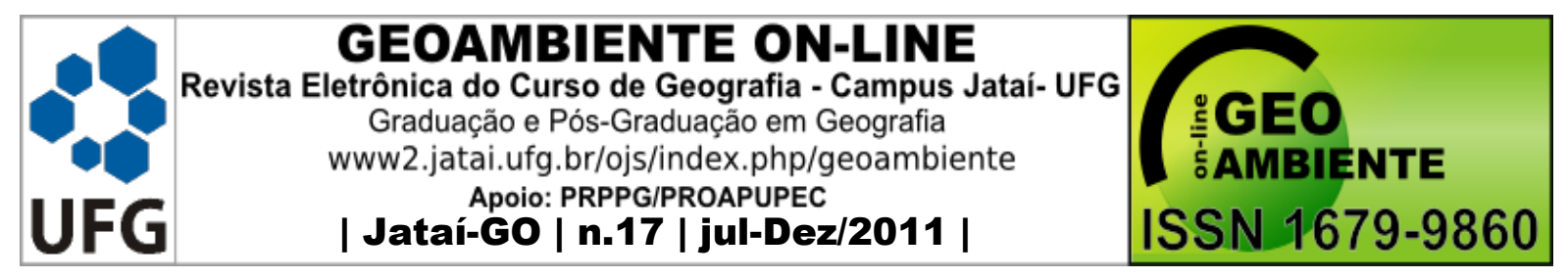

Palavras chaves: GPS, posicionamento relativo, determinação altimétrica, monitoramento de geleiras.

\section{Abstract \\ ALTIMETRIC DETERMINATION AND DEM GENERATION FOR GLACIER WANDA, KING GEORGE ISLAND, BY GLOBAL POSITIONING SYSTEM AND TRIGONOMETRICAL LEVELING}

This study aims to determine orthometric heights and the generation of three-dimensional model of the surface at Wanda glacier located on King George Island, Antarctic Peninsula. Due to logistical difficulties in accessibility of these environments, data from Numerical Models of Terrain must be allow obtaining volumetric data of glaciers for temporal analysis and inference of the direction of ice flow and also changes in glacial dynamics. The GPS data, obtained by the static relative fast method with a single frequency topographic receiver, were post-processed for differential correction and the coordinates and altitude for the ellipsoid were converted to the local topographic system by calculating the geoid undulation based on geopotential model EGM96. With the obtained data was generated three-dimensional model of the surface to Wanda glacier, which indicates a profile with a slope toward the front area. This drop may be related to the topography of the basement rock. A topographic surface with a greater slope observed with the model can provide a local acceleration of the ice flow velocity for Wanda glacier.

Keywords: GPS, positioning relative altimetric determination, monitoring of glaciers.

\section{Resumen}

DETERMINACIÓN ALTÍMETRO Y MODELO DIGITAL DEL TERRENO DEL

\section{GLACIAR WANDA, ISLA REY JORGE, PARA EL SISTEMA DE POSICIONAMIENTO GLOBAL Y DE NIVELACIÓN TRIGONOMÉTRICA}

Este estudio pretende determinar las alturas ortométricas y la generación de un modelo tridimensional de la superficie glaciar Wanda situado en la Isla Rey Jorge, Península Antártica. Debido a la dificultad logística de la accesibilidad de estos ambientes, el tiempo de recolección de datos de modelos numéricos del terreno debe obtener datos volumétricos para 


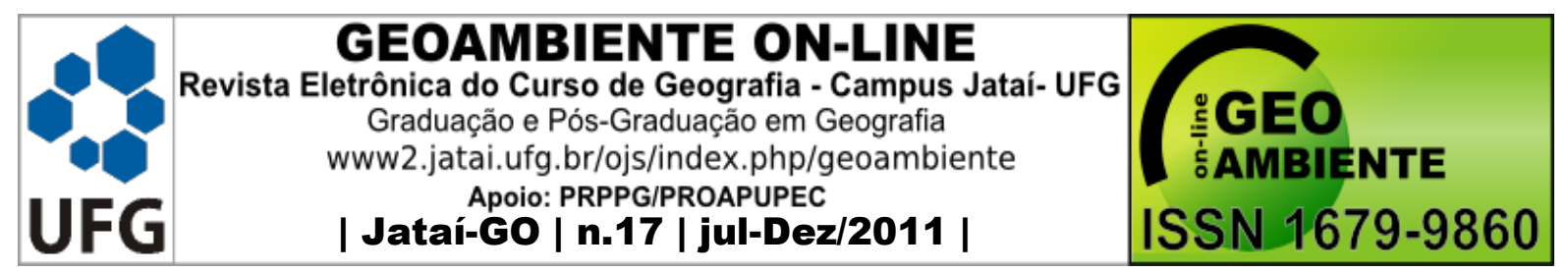

el análisis temporal de los glaciares, la inferencia de la dirección del flujo de hielo y cambios en la dinámica glacial. Los datos de GPS obtenidos por el método estático y cinematico con una frecuencia del receptor simple (GTRA) fueron post-procesado para corrección diferencial de altimetría y las coordenadas en el elipsoide se convierten en el sistema local de medición mediante el cálculo de la ondulación del geoide sobre la base de modelo EGM96 geopotencial. Con los datos se generó un modelo tridimensional de la superficie del glaciar Wanda. El análisis de este modelo indica un perfil con una pendiente hacia la zona frontal. Esta pendiente puede estar relacionada con la topografía de la roca basal y la pérdida de masa de hielo del glaciar en las últimas décadas. Una superficie con una pendiente mayor, verificado con el modelo, puede proporcionar una aceleración de la velocidad del flujo del glaciar Wanda.

Palabras clave: GPS, posicionamiento relativo, la determinación de altimetría, la vigilancia de los glaciares

\section{INTRODUÇÃO}

O Sistema de Posicionamento Global (GPS) vem sendo utilizado nas mais variadas atividades de posicionamento horizontal e vertical, pois oferece uma série de vantagens em relação aos métodos convencionais usados em Topografia.

Com o crescente interesse pela utilização do GPS para medições geodésicas de curta distância, foram desenvolvidos vários métodos de posicionamento, dentre os quais se destaca o método relativo estático. Este método consiste em posicionar um receptor GPS em um ponto de coordenadas conhecidas e outro receptor no ponto no qual deseja determinar as suas coordenadas. A principal vantagem do método é a sua precisão, quando comparado com outros métodos de posicionamento.

Estudos de Corseuil e Robaina (2003) demonstram a possibilidade da utilização do Sistema de Posicionamento Global (GPS) de forma precisa nos levantamentos altimétricos, desde que se efetue a modelagem da ondulação geoidal. Segundo Monico (2000), existem vários modelos de ondulação geoidal disponíveis atualmente, dentre os quais pode-se destacar o EGM 96 (Earth Goddard Model 96). O EGM96 é o modelo terrestre de referencia do Sistema Geodésico World Geodetic System 1984 (WGS84) e geralmente estão disponíveis 


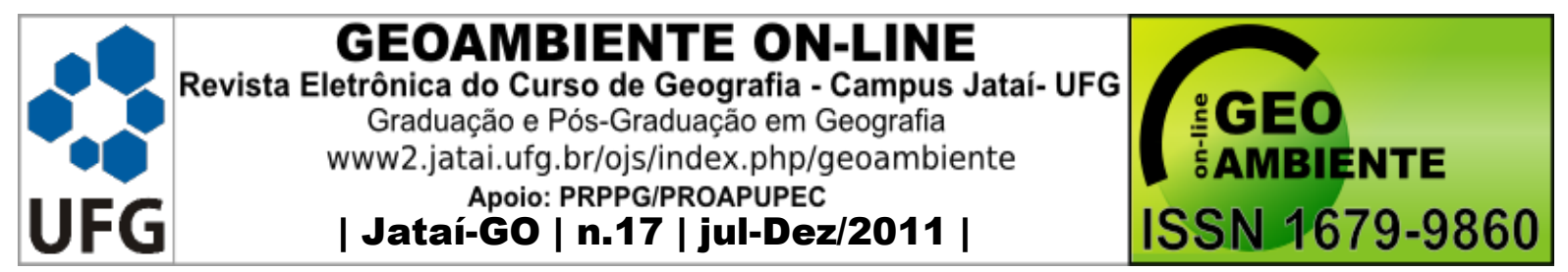

nos software comerciais de processamento de dados GPS.

Devido à dificuldade de acessibilidade logística destes ambientes, dados de Modelos Numéricos do Terreno permite obter dados volumétricos das geleiras, e assim efetuar uma análise temporal de mudanças na espessura, direção de fluxo de gelo e dinâmica glacial. Adicionalmente, investigações na área de estudo possuem relevância para o monitoramento da geleira diante da variabilidade climática evidenciada na área de estudo

Este trabalho objetiva determinar altitudes ortométricas e geração de Modelo Tridimensional de Superfície na área da geleira Wanda, ilha Rei George, Península Antártica. Poucas pesquisas têm sido feitas para determinar a espessura do gelo e a geometria da topografia superficial no campo de gelo Kráków, bacia de drenagem na qual se insere a geleira Wanda.

Não há monitoramento altimétrico na área de estudo que poderia determinar a perda de massa de gelo.

\section{2. ÁREA DE ESTUDO}

A geleira Wanda (Figura 1) está localizada na ilha Rei George, Península Antártica, pertence ao campo de gelo Kraków e tem 1,63 km² de área (Arigony-Neto, 2001).

Figura 1 - Localização da geleira Wanda na Península Antártica. 


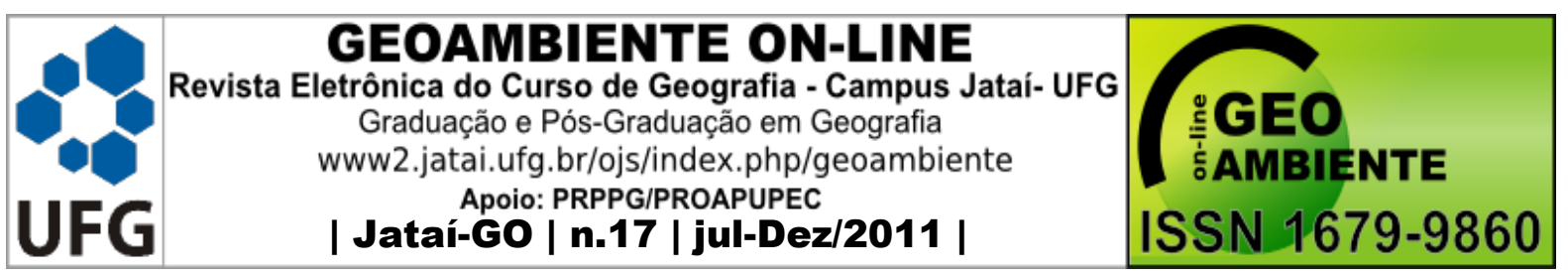

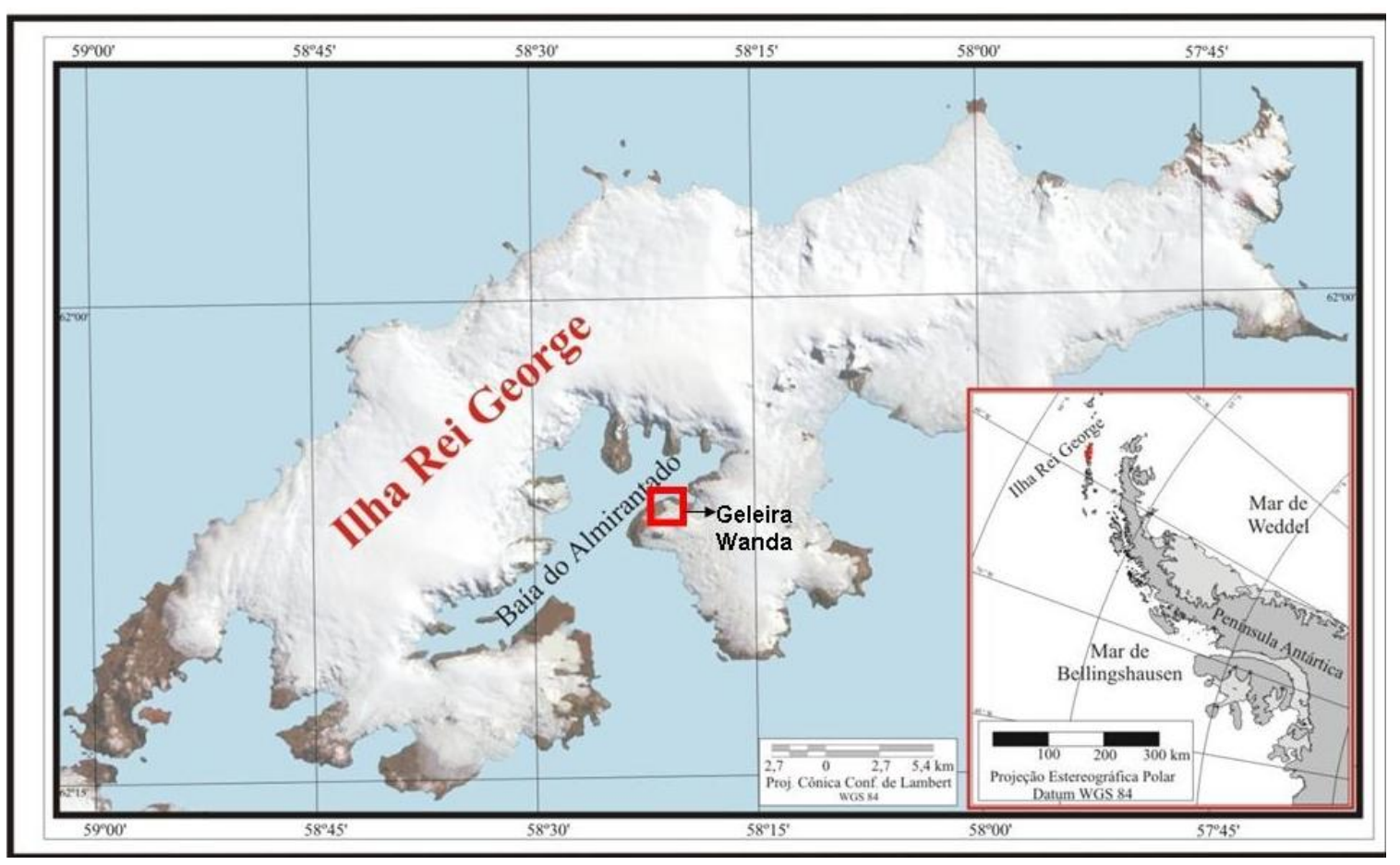

O clima na ilha Rei George é determinado pelas sucessivas passagens de sistemas ciclônicos, em sua maioria originários do setor sudeste do oceano Pacífico. Esses sistemas transportam ar relativamente quente e úmido. O clima apresenta pequenas variações na temperatura atmosférica ao longo do ano, alta umidade relativa do ar (entorno de 82\%) (Binjanta, 1995).

Pesquisas de Macheret et al. (1997) indicam que a massa de gelo da ilha Rei George está no ponto de fusão sob pressão (Macheret e Moskalevsky, 1999; Pfender 1999; Simões, et al., 2004). Mantos de gelo frio com temperaturas abaixo do ponto de degelo sob pressão e pouca quantidade de água de degelo são distintas de campos de gelo temperados (temperaturas sob o ponto de fusão sob pressão), onde a água de degelo está presente dentro do corpo de gelo (Patterson, 1994).

A geleira Wanda, que flui para a enseada Martel, tem passado por distintas fases de retração no período em que ocorreram mudanças na orientação principal do fluxo de gelo. Cada fase foi acompanhada pela formação de depósitos e geoformas. Desde a década de 1979 ocorreu a aceleração de seu recuo (Rosa et al., 2009). 


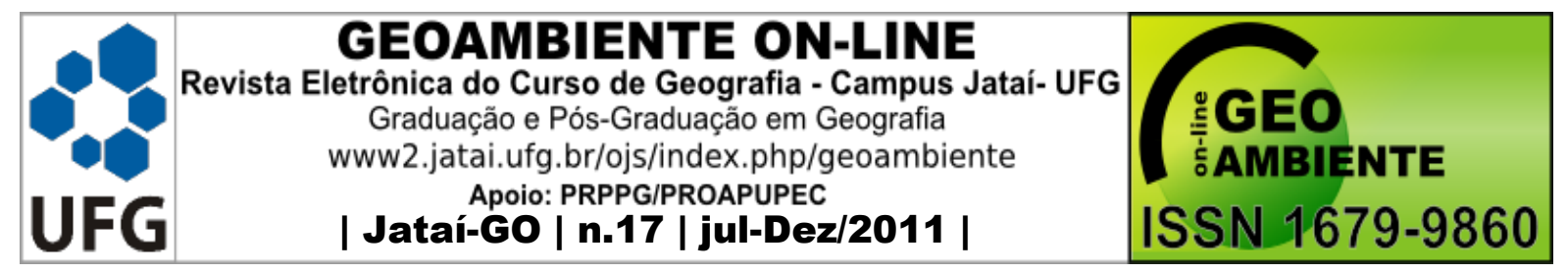

\section{MATERIAIS E MÉTODOS}

Para determinar as altitudes foi realizada coleta de dados pela acessibilidade com o uso de pós-processamento diferencial dos dados (rover) levantados pelos receptores GPS. Estes dados foram obtidos pelo método relativo estático rápido com um receptor topográfico de simples freqüência (GTRA), cuja precisão alcançada no pós-processamento dos dados é de $5 \mathrm{~mm} \pm 1 \mathrm{ppm}$ (SOKKIA, 1999). Também foram obtidas altitudes ortométricas por nivelamento trigonométrico com estação total. No método de posicionamento relativo estático e cinemático as coordenadas de um ponto desconhecido são determinadas em relação a um ponto de coordenadas conhecidas (estação base) (Monico, 2007). A antena do receptor base foi instalada na Estação Antártica Comandante Ferraz (estação base), localizado na Ilha Rei

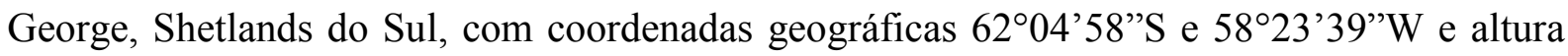
geométrica de 57,53 metros. Esta estação de referência é mantida e gerida pelo Instituto Brasileiro de Geografia e Estatística (IBGE).

Os dados foram convertidos para o formato RINEX (Receiver Independent Exchange), que é um formato universal utilizado para entrada de dados na maioria dos programas computacionais de processamento de dados obtidos com receptores GPS, e pós processados para a correção diferencial no software EZserver e Topcon tools (TOPCON, 1993).

As coordenadas altimétricas relativas ao elipsóide $(\mathrm{Z}$ ou h) dos pontos relacionadas ao sistema WGS 84 foram transformadas para o sistema topográfico local, através do procedimento descrito por Hofmannw Wellenhof et al. (1997).

As altitudes geométricas $(\mathrm{h})$ foram transformadas em ortométricas $(\mathrm{H})$, através do conhecimento da ondulação geoidal (N) do local. Segundo Merege Filho (1993), para determinação das altitudes ortométricas a partir das geométricas, foi necessário conhecer a diferença entre elas. Esta diferença é denominada de ondulação geoidal $(\mathrm{N})$ e pode ser determinada pela equação: $\mathrm{H}=\mathrm{h}-\mathrm{N}$, considerando-se como referência altimétrica o modelo EGM96 (Earth Gravity Model 1996). Assim, utilizando-se a ferramenta para cálculo da ondulação geoidal (considerando-se elipsóide WGS84 e modelo geoidal EGM96), disponível na página da Agência Nacional de Dados Geoespaciais dos Estados Unidos (NGA, 2005 antiga NIMA, foram obtidas as ondulações para cada um dos pontos considerados. O 


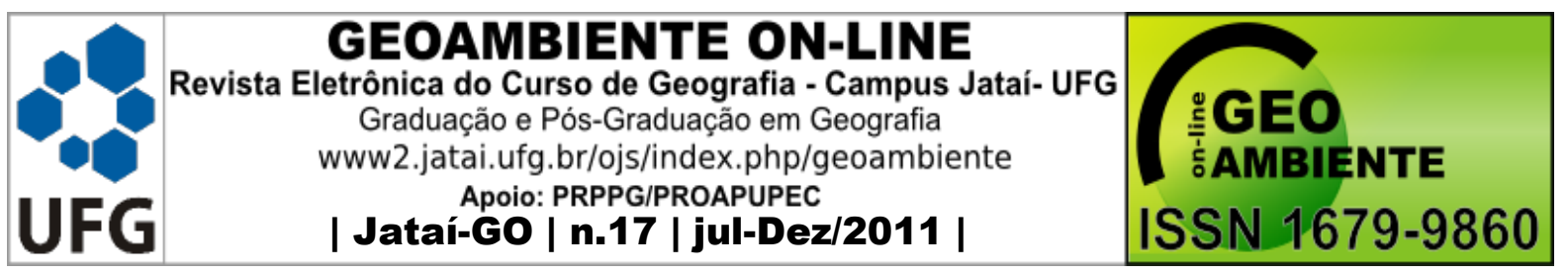

NGA/NASA Geoid Height File consiste em uma grade regular com espaçamento de 15'x 15' que usa o Modelo Geopotencial EGM96.

No software de interpolação SURFER (Golden Software, 1999) foi gerado o modelo de superfície 3D. Foi utilizada a malha de amostragem aleatória devido à distribuição casual dos pontos interpolados. O método de interpolação utilizado foi o de Krigeagem de acordo com a fidelidade aos dados originais proporcionada e a relativa suavidade nas curvas. A interpolação por krigeagem utilizada no SURFER é a ordinária pontual e sua aplicação foi relacionada a continuidade espacial sobre os dados obtidos.

\section{RESULTADOS E DISCUSSÃO}

$\mathrm{Na}$ Tabela 1 são mostradas as coordenadas horizontais $(\mathrm{E}, \mathrm{N})$, os valores da altitude ortométricas obtidas por nivelamento trigonométrico e com o GPS, nos diferentes tempos de ocupação dos pontos.

Tabela 1 - Pontos e coordenadas ortométricas pós-processadas.

\begin{tabular}{|c|c|c|c|}
\hline Ponto & $\mathrm{E}(\mathrm{m})$ & $\mathrm{N}(\mathrm{m})$ & $\mathrm{z}(\mathrm{m})$ \\
\hline 1 & 429398 & 3113137 & 53.633 \\
\hline 2 & 429779 & 3112090 & 279.080 \\
\hline 3 & 429391 & 3112643 & 218.079 \\
\hline 4 & 430153 & 3112886 & 146.143 \\
\hline 5 & 430153 & 3112886 & 283.782 \\
\hline 6 & 429717 & 3113159 & 59.37 \\
\hline 7 & 429885 & 3113128 & 86.578 \\
\hline 8 & 429320 & 3112938 & 57.7 \\
\hline 9 & 429225 & 3113030 & 37.76 \\
\hline 10 & 429765 & 3113065 & 67.67 \\
\hline 11 & 429649 & 3113183 & 56.87 \\
\hline 12 & 429192 & 3113110 & 15.39 \\
\hline 13 & 429698 & 3112851 & 80.621 \\
\hline 14 & 429544 & 3113001 & 66.183 \\
\hline 15 & 429285 & 3113117 & 51.137 \\
\hline 16 & 429585 & 3113115 & 15.116 \\
\hline
\end{tabular}




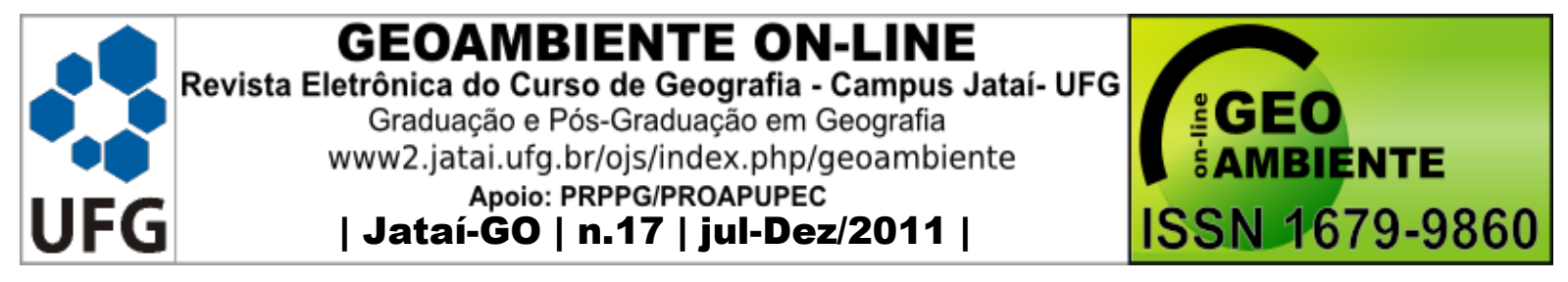

O uso de um receptor estacionário para calcular correções posicionais e pseudodistâncias proporcionou a precisão planimétrica e altimétrica de aproximadamente 5 metros, dependendo do comprimento da linha base. Como as linhas bases calculadas possuem poucos quilômetros de distância (até $1000 \mathrm{~km}$ ) obtem-se acurácia de 1 a 5 metros (Monico, 2007). Os valores de menor acurária obtidos podem estar relacionados com o reduzido tempo de coleta dos pontos relacionados.

Diante da precisão obtida pelo método topográfico por nivelamento topográfico, a utilização do GPS associada ao método de posicionamento estático e modelagem da ondulação geoidal também pode providenciar dados de forma relativamente precisa nos levantamentos altimétricos para a área de estudo.

O Modelo Tridimensional de Superfície da geleira Wanda (Figura 2) indica um perfil com uma pendente inclinada em direção a área frontal. Esta pendente pode estar relacionada à topografia do embasamento rochoso e ao controle geológico estrutural da área de estudo. Uma superfície de maior declividade pode causar uma aceleração local da velocidade de fluxo da geleira Wanda. Este processo pode estar associado à provável diminuição da espessura da frente à geleira observada em campo e ao seu processo de retração.

O Modelo Tridimensional de Superfície gerado para a geleira Wanda possibilita análises temporais de cálculo de volume e mudanças na dinâmica glaciológica. A partir do modelo podem ser realizadas inferências do sentido do fluxo de gelo de acordo com as condições atuais da geleira.

De acordo com a configuração topográfica visualizada no modelo acima observa-se que há uma pendente inclinada com sentido SE-NO, indicando o sentido de fluxo do gelo determinada pela topografia. Infere-se que pode haver um provável aumento de velocidade do fluxo de gelo relacionado a uma pendente topográfica mais íngreme no setor mais elevado da geleira (em direção a área de acumulação). O aumento de velocidade pode estar relacionado com o aumento de deslize devido ao gradiente topográfico. 


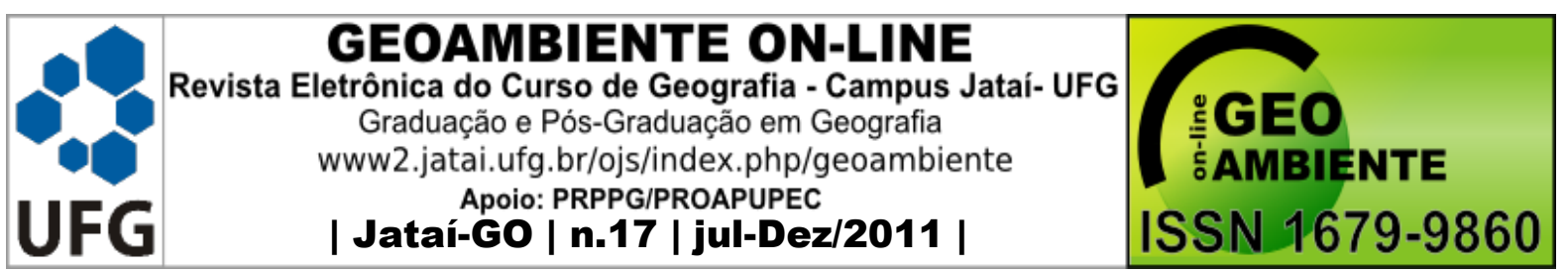

Figura 2 - Modelo Tridimensional de Superfície correspondendo à área de estudo da geleira Wanda.

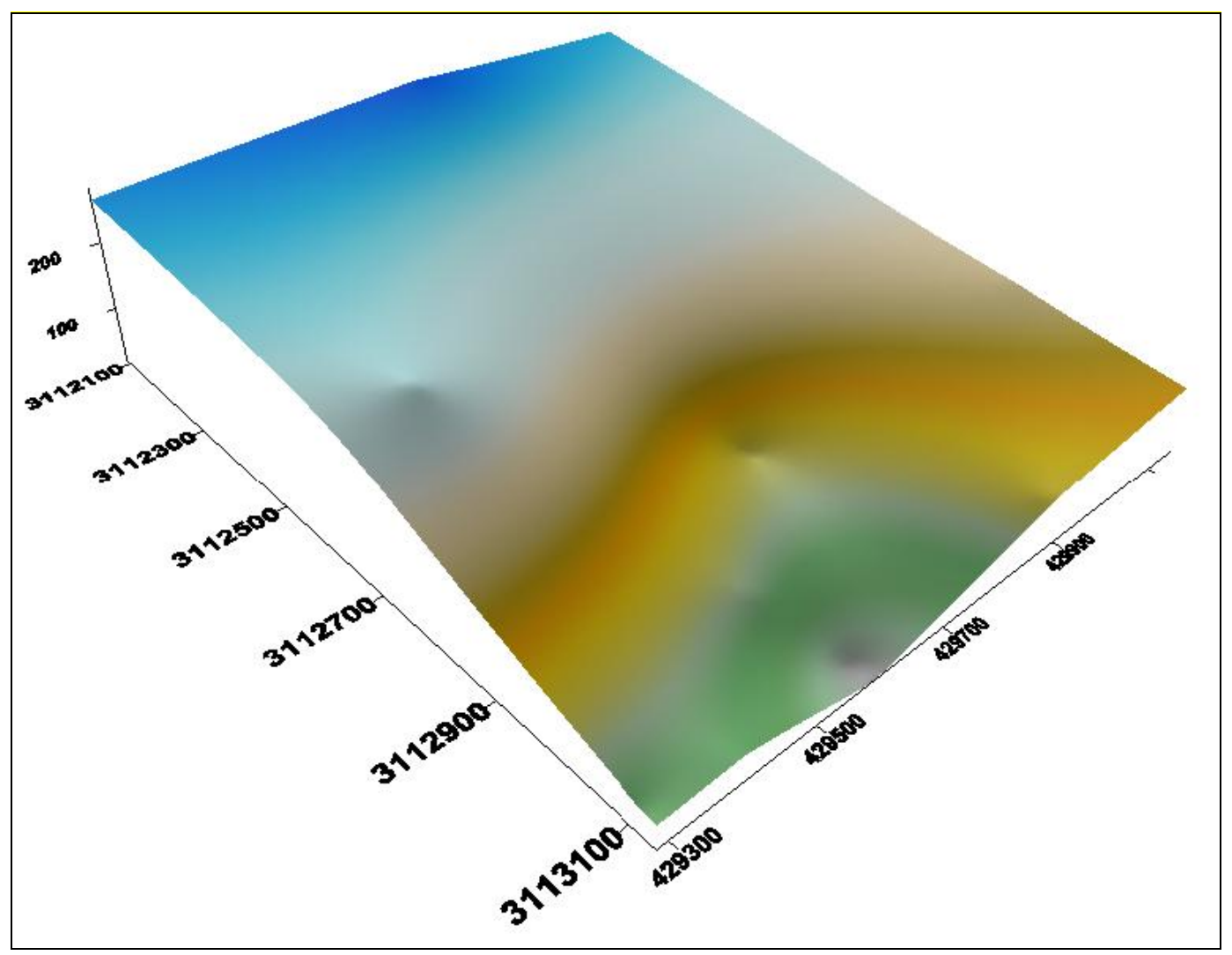

\section{CONCLUSÕES E RECOMENDAÇOES}

Diante do processo de retração evidenciado para a geleira Wanda e a ausência de de dados históricos que possibilitem o monitoramento altimétrico na área de estudo, dados de Modelos Numéricos do Terreno são úteis obter dados volumétricos das geleiras e, assim, permitir efetuar uma análise temporal de mudanças na espessura, direção de fluxo de gelo e dinâmica glacial.

O modelo Tridimensional de Superfície gerado indica perfil da geleira com uma pendente em direção a área frontal. Esta pendente pode estar relacionada à topografia do embasamento rochoso e a uma perda de massa de gelo nas últimas décadas.

Quanto ao Modelo Numérico produzido ressalta-se a necessidade de um modelo de ondulação geoidal local para escalas de mapeamento de maior detalhe. 


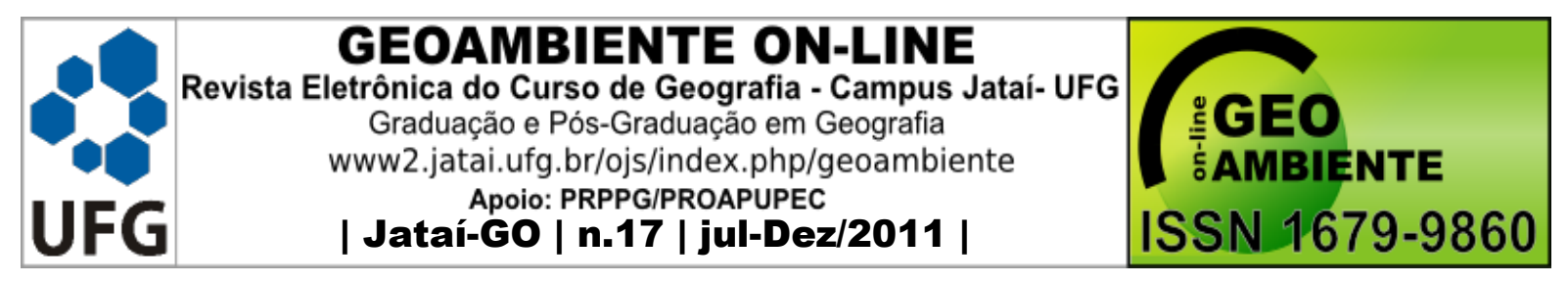

Ressalta-se que resultados altimétricos mais precisos podem ser conseguidos com um maior número de pontos de controle obtidos na área de estudo, o que pode proporcionar a geração de MDT de maior resolução. Dados de Áster GDEM podem ser utilizados para a validação da precisão do Modelo Tridimensional de superfície gerado.

\section{AGRADECIMENTOS}

Ao PROANTAR (Programa Antártico Brasileiro), ao INCT da Criosfera CNPq, ao Departamento de Geodésia da UFRGS, ao Clube Alpino Paulista, ao Lagemar Laboratório de Geologia Marinha da Universidade Federal Fluminense e ao Instituto Presbiteriano Mackenzie (INPE-CRAAM).

\section{REFERENCIAS}

ARIGONY-NETO, J. Determinação e interpretação de características glaciológicas e geográficas com sistema de informações geográficas na Área Antártica Especialmente Gerenciada da baía do Almirantado, ilha Rei George, Antártica. Porto Alegre: Universidade Federal do Rio Grande do Sul, Dissertação de mestrado. 2001. 84 p.

BIJANTA, R. Local surface energy balance of the Ecology Glacier, King George Island, Antarctica: measurements and modeling. Antarctic Science 7, 1995, p. 315-325.

CORSEUIL, C. W.; ROBAINA A. D. Determinação altimétrica através do sistema de Posicionamento Global. Revista Ciência Rural, Santa Maria, v.33, n.5, p.673-678, jul-ago,. 2003.

HOFMANN-WELLENHOF, B.; LICHTENEGGER H.; COLLINS J. Global positioning system: theory and practice. New York : Springer-Verlag Wien, 1997. 389p.

MACHERET Y.; MOSKALEVSKY, M.; SIMÕES, J.C.; LADOUCH, L. Radio-echo sounding of King George Island ice cap, South Shetland Islands, Antarctica. Mater Glyatsiol Issled, 83, 1997, p 121-128.

MACHERET, Y.; MOSKALEVSKY, M. Study of Lange Glacier on King George Island, Antarctica. Annals of Glaciology, 29, 1999, 202-206.

MEREGE FILHO, P. A. Confiabilidade de altitudes determinadas com GPS. Fator GIS. Revista do Geoprocessamento, Curitiba, 03, p.16-17. 1993. 


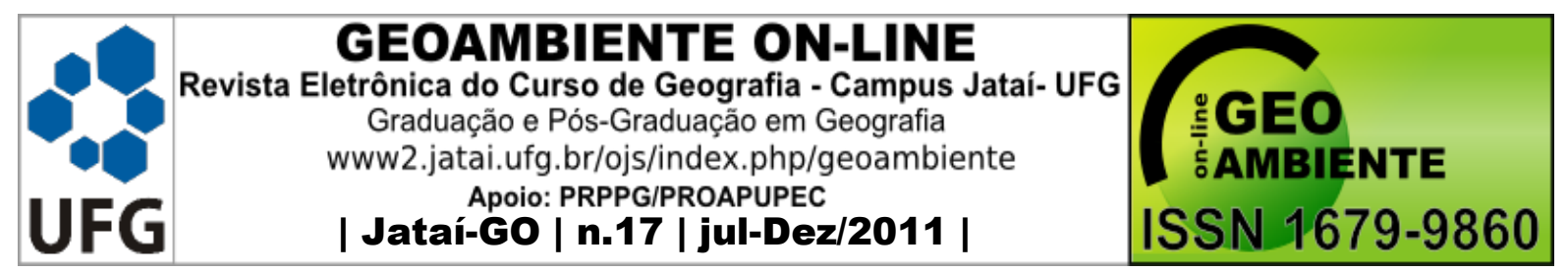

MONICO, J.F.G. Posicionamento pelo GNSS: descrição, fundamentos e aplicações. São Paulo, Editora UNESP, 2007. 476 p.

PATERSON, W.S.B. The Physics of Glaciers. Elsevier, Oxford, 1994. 480 p.

PFENDER, M. Topographie und Glazialhydrologie von King George Island, Antarktis. Diplomarbeit im Fach Geophysik, Westfälischen Wilhelms-Universität Münster, 1999. 99 p. ROSA, K.K.; VIEIRA, R.; FERRANDO, F.J.; SIMÕES, J.C. Feições sedimentológicas e geomorfológicas do ambiente de deglaciação das geleiras Wanda e Ecology, ilha Rei George. Antártica. Revista Pesquisas em Geociências. 37(1), 2009, p. 315-326.

SIMÕES, J.S.; FERRON, F.A.; BERNARDO, R.T.; ARISTARAIN, A.J.; STIÉVENARD, M.; POURCHET, M.; DELMAS, R.J. Ice core study from the King George Island, South Shetlands, Antarctica. Pesquisa Antártica Brasileira, 4, 2004, p. 9-23.

SOKKIA. Operator. Manual: GSS1A, GPS Survey Receiver. Lenexa, USA, 1999. 5-5. nãopaginado.

SURFER, version 8.0. Apostila do Curso Básico de Surfer - versão 8.0. Surface Mapping System

Copyright $\odot$, Golden Software, Inc. (informações em http://www.goldensoftware.com). TOPCON AMERICAN CORPORATION. TOPCON GPS Receivers- GP-R1, GP-R1D, GPR1DP. Version 7 A: Operating Manual. New Jersey, USA, 1993. 219p. 